\title{
The Maya Religion (Review)
}

\author{
Helena Dyndová
}

The Maya religion is a comprehensive and high-quality introductory monograph to the religious life of Ancient Mayas. It can be used as an extremely useful guide, not only by the academic community, to which it has been dedicated in the first place, but thanks to its readable and fluent style, it will be beneficial even for laymen or enthusiasts. At the same time, this book is useful not only for those interested in the area of Mesoamerica, but for a variety of experts on ancient cultures and on a wider scale, with regard to its remarkable meta-methodological scope, for religious studies scholars in general as well.

Even only a brief look on the table of contents indicates that the author focuses on Maya religious life in accordance with detailed and conscientiously written introductory handbooks: from history and geography, to the categorization of available archaeological and literary sources, the social organization and city architecture, and finally to the role of the king, nobility, and other religious specialists. A great part of this book is naturally dedicated to deities, myths and rites, and inseparably related topics such as the importance of astronomy and astrology for calendar feasts, the Maya concept of the soul, and Maya cosmology.

We could probably end the book review at this point and evaluate the book based on its relationship to the current scientific knowledge, stylistic skills, etc. However, this book is not as linear or shallow. Besides its unquestionably erudite range, the reader, no later than after the second chapter, enters the jungle of interpretations and pre-understandings of how the study of the Maya has been approached. Step by step, the reader is slowly immersed in the universe of motivations and ulterior motives, with which these interpretations were created. After all, the nature of the sources and history of Maya studies calls for this approach.

The author systematically guides the reader through all the topics, introducing relevant approaches to these issues. And simultaneously, in the background of the discussed aspects of Maya religion, the reader will begin to follow the methodological questions that go beyond the given area of study and which sometimes overtake and form the chapter. This leads to continuous reasoning about the availability and credibility of sources, to which the author shows great respect. Thus, the reader learns to ask, over every aspect of Maya religion: does the primary material possess this quality or is it our secondary interpretation? (p. 170) And this skill is both helpful and much needed in the lack or absence of empirical evidence. 
In this way, the interpretations of the post-colonial Christian administration, as well as romanticizing (an inspiring chapter about human sacrifice, p. 246) or hypercritical postmodern approaches (the Maya had no gods) gradually begin to be considered. The famous theories of the pioneers of Maya studies are discussed alongside the undisputed influence of the historian of religion Mircea Eliade and the generation of his followers. The author provides a fair reassessment of the limits, pitfalls and benefits of comparative and synthesizing theories on the one hand, and the specific and highly specialized approaches on the other hand and tries to walk the line. To the credit of her research, she manages this uneasy task sensitively, without unnecessary mocking, irony or an implacably critical tone, which can be sometimes observed in academic polemics, when the expert disagrees with another interpretative tradition.

Moreover, the reasoning goes beyond scholarly analysis. In the same way as all sources are necessarily interpreted or explained by scientists themselves, scholars also do not live in an academic vacuum. Their texts influence society, which - in turn - affects them. It is only commendable that the author was not afraid to deal with important contemporary trends, which, at face value, have little to do with academic Maya studies, but which are of a great importance to the whole subject nevertheless. Accordingly, the author concentrates on modern environmentalism (co-creating a new theory of classical collapse, p. 51), feminism (fresh criticism of the Goddess Ixchel's “Smurfette principle”, p. 170), or the craving for Maya spirituality as a source of spirituality to the new age/contemporary alternative spiritual movement (i.e. scholars writing about "energy" or "transformation of consciousness" in Ancient Maya context, p. 159).

All this intertwining of "sources we have" and "interpretations we introduce" then culminates in a sort of grand finale; the last section of the monograph that summarizes the entire history of approaches to Maya religious chronologically, the short addendum of Czech and Slovak Maya studies, contemporary spirituality, pop culture, and the 2012 millennial expectations included. But considering how important is the metod of discourse analysis for the author and how the whole book contains a number of references to the last chapter, the final chapter could do with even more elaboration and a more complex approach.

The following matter of dispute is not about what is contained in the book, but what is missing. For example, it is somewhat confusing that despite the constant reminders of the researchers' points of view, the author herself does not give any hints and explicitly reveal her "individual partiality and emotions" (p. 321) to the research subject, which is a pity. As the author puts it: "A completely neutral approach to the past is virtually impossible, and the researcher's personality and the 'Zeitgeist' that shaped her/him can never be completely removed." (p. 321). That is true; but applies to her as well.

With regard to the reflection of archaeological and literal sources, a more theoretical evaluation of the Maya religious syncretism and use of folklore records would complete this "source family", since the author occasionally draws a comparison between contemporary and Ancient Maya customs - albeit with caution. Likewise, 
a more in-depth methodological analysis of gods other than the prominent god D, the goddess $\mathrm{O}$ (I) and the K'uk'ulkan would be surely appreciated, since in these three cases, the analysis was very inspiring.

Finally, this academic publication lacks indexes or any other apparatus, which is very user-unfriendly. Furthermore, the Maya alphabet table, the solar and lunar calendar tables, and the Schellhas's table of deities are dispersed in the book and that makes it difficult to work with them.

These small final touches notwithstanding, this monograph is beyond all doubt not only an extremely important contribution to current Maya studies, but also a useful tool for researchers in ancient (non)literary cultures and, for its methodological aptitude, for religious studies scholars as well. The discourse analysis implicitly applied to old Maya religion is a refreshing attitude, since not only religion is in constant dialogue with the "profane world" of political agenda, economy, and the prevailing worldview, but so are the scholars who form the image of these civilizations. This meta-methodological technique is certainly a complicated and multi-levelled one, but The Maya Religion accepted this challenge with grace.

\section{REFERENCES}

Kostićová, Zuzana Marie, Náboženství Mayů [Maya Religion], Praha: Karolinum 2018, $357 \mathrm{p}$. 